\title{
Preservação de sêmen refrigerado de cioba com diluentes e atmosfera modificada
}

\author{
Eduardo Gomes Sanches ${ }^{(1)}$ e Vinicius Ronzani Cerqueira(2)
}

\begin{abstract}
(1)Secretaria de Agricultura e Abastecimento, Agência Paulista de Tecnologia dos Agronegócios, Instituto de Pesca, Núcleo de Pesquisa e Desenvolvimento do Litoral Norte, Rua Joaquim Lauro Monte Claro Neto, no 2.275, Itaguá, CEP $11680-000$ Ubatuba, SP. E-mail: esanches@pesca.sp.gov.br (2)Universidade Federal de Santa Catarina, Departamento de Aquicultura, Rodovia Ademar Gonzaga, no 1.346, Itacorubi, CEP 88034-001 Florianópolis, SC. E-mail: vrcerqueira@cca.ufsc.br
\end{abstract}

Resumo - O objetivo deste trabalho foi avaliar o efeito de diferentes diluentes, em atmosfera normal e modificada, na preservação de sêmen refrigerado da cioba - Lutjanus analis. Amostras de sêmen de 30 peixes foram avaliadas quanto à taxa de motilidade, duração da motilidade, concentração espermática e espermatócrito. Para a refrigeração a $4^{\circ} \mathrm{C}$, três diferentes diluentes, com distintas composições iônicas e valores de $\mathrm{pH}$ distintos, foram testados em atmosfera normal e atmosfera modificada (100\% oxigênio). Posteriormente, um teste de fertilização foi realizado para avaliar a viabilidade do sêmen refrigerado. No experimento de refrigeração, a taxa de motilidade e a duração da motilidade foram adequadas, durante 72 horas, para os diluentes $\mathrm{A}$ ( $48 \pm 7 \%$; $190 \pm 26 \mathrm{~s})$ e B (41 $\pm 4 \% ; 160 \pm 22 \mathrm{~s})$ em atmosfera normal. Na atmosfera modificada, a qualidade do sêmen caiu drasticamente durante as primeiras 24 horas, independentemente do diluente utilizado, e não houve vantagem em sua utilização. A taxa de fertilização com sêmen refrigerado por 24 horas, tratado com diluente $\mathrm{A}$, não diferiu daquela com sêmen fresco, e ambas foram superiores à obtida com sêmen refrigerado por 48 horas.

Termos para indexação: Lutjanus analis, reprodução, maricultura.

\section{Preservation of refrigerated sperm of the mutton snapper with diluents and modified atmosphere}

\begin{abstract}
The objective of this study was to evaluate the effect of different diluents at normal and modified atmosphere on the preservation of refrigerated sperm of the mutton snapper Lutjanus analis. Sperm samples of 30 fishes were evaluated for motility rate, motility time, sperm concentration and spermatocrit. For the refrigeration at $4^{\circ} \mathrm{C}$, three different diluents with distinct ionic compositions and $\mathrm{pH}$ values were tested at normal and at modified atmospheres (100\% oxygen). Afterwards, a fertilization test was accomplished to evaluate the viability of the refrigerated sperm. In the refrigeration experiment, the motility rate and the motility time were maintained appropriate for 72 hours for the extender A $(48 \pm 7 \%, 190 \pm 26 \mathrm{~s})$ and B $(41 \pm 4 \%$, $160 \pm 22 \mathrm{~s}$ ) at normal atmosphere. At the modified atmosphere, the sperm quality fell drastically during the first 24 hours, independently of the utilized diluent, and there was no advantage in its use. The fertilization rate with refrigerated sperm for 24 hours, treated with the diluent $\mathrm{A}$, was not different from that of fresh sperm, and both were higher than the one obtained with refrigerated sperm for 48 hours.
\end{abstract}

Index terms: Lutjanus analis, reproduction, mariculture

\section{Introdução}

A preservação do sêmen de peixes, por meio da técnica de refrigeração, apresenta baixa complexidade e possibilita grande aplicação prática nos procedimentos de reprodução. Esta técnica tem como objetivo manter a viabilidade espermática sob refrigeração a $4^{\circ} \mathrm{C}$, por horas ou dias, para que o sêmen possa ser utilizado posteriormente no processo de fertilização. Esta metodologia dispensa a manipulação dos machos, nesse momento, e libera tempo para o monitoramento da ovulação das fêmeas, o que proporciona melhores resultados nos procedimentos de reprodução (Oliveira et al., 2007).

$\mathrm{O}$ resfriamento estende a viabilidade temporal do sêmen não diluído por algumas horas. Esse efeito pode ser explicado pela redução da atividade metabólica dos espermatozoides a temperaturas abaixo da fisiológica. O resfriamento, após sua combinação com soluções diluentes imobilizadoras da motilidade, que mimetizam a composição iônica e a osmolalidade do plasma seminal, tem sido efetivo em potencializar a longevidade, sem promover mudanças significativas da qualidade do sêmen (Peñaranda et al., 2010). 
Diversos fatores podem influenciar o sucesso da refrigeração do sêmen de peixes, como a utilização de diluentes e adequadas condições de estocagem. Em sêmen de caprinos, a refrigeração reduziu o catabolismo espermático e diminuiu a atividade metabólica do espermatozoide, o que possibilitou sua armazenagem, embora o choque pelo frio tenha acarretado redução da taxa de motilidade espermática com efeitos negativos sobre a capacidade de fertilização (Bezerra, 2010). Para minimizar esses efeitos no sêmen de peixes, procura-se garantir a composição iônica, o $\mathrm{pH}$, a pressão osmótica do diluente e, ainda, as condições do ambiente de estocagem dos espermatozoides, para a manutenção da estabilidade natural do plasma seminal. Por esta razão, os diluentes têm sido desenvolvidos para manter estáveis as condições físicoquímicas do plasma seminal, durante o período de estocagem, e possibilitar uma alta taxa de motilidade espermática (Tan-Fermin et al., 1999). O desenvolvimento de diluentes específicos para o sêmen refrigerado da enguia européia (Anguilla anguilla) têm otimizado as taxas de fecundação (Peñaranda et al., 2010).

Ao se considerarem as condições de estocagem, deve-se observar que o oxigênio é um fator crítico na preservação espermática durante a refrigeração. Bencic et al. (2000) observaram uma expressiva melhoria na sobrevida espermática, quando o sêmen de salmonídeos foi submetido à refrigeração em atmosfera modificada (100\% oxigênio).

A cioba Lutjanus analis se distribui ao longo do Oceano Atlântico, de Massachusetts (EUA) até Santa Catarina (Brasil). Pode chegar a $80 \mathrm{~cm}$ e pesar $11 \mathrm{~kg}$ aos 14 anos de idade, a maturidade sexual deste peixe ocorre aos quatro anos, e seu comprimento pode ser superior a $50 \mathrm{~cm}$ (Claro \& Lindeman, 2008). No Sudeste do Brasil, que abrange a área deste trabalho, L. analis é uma das principais fontes de renda dos pescadores artesanais, além de ser muito apreciada na pesca esportiva. Freitas et al. (2011) destacaram que, entre as diversas espécies de lutjanídeos que ocorrem no Brasil, essa é a que apresentou as melhores perspectivas para cultivo, tendo-se adaptado facilmente ao cativeiro e aceitado tanto dietas frescas como rações comerciais. Cultivos experimentais no Caribe e na Colômbia vêm mostrando o potencial dessa espécie para a piscicultura marinha (Benetti et al., 2002; Botero \& Ospina, 2003), entretanto, a dificuldade na obtenção de formas jovens é o principal fator limitante para seu cultivo. Assim, é necessário o desenvolvimento de pesquisas na área de reprodução dessa espécie, em busca de tecnologias que viabilizem seu cultivo.

O objetivo deste trabalho foi avaliar o efeito de diferentes diluentes, em atmosfera normal e modificada ( $100 \%$ oxigênio), na preservação de sêmen refrigerado da cioba L. analis.

\section{Material e Métodos}

Cinquenta exemplares de $L$. analis foram coletados na região litorânea de Ubatuba, SP, entre outubro e novembro de 2007. Os exemplares foram mantidos em tanques-rede, de $2 \times 2 \times 2 \mathrm{~m}\left(8 \mathrm{~m}^{3}\right)$, instalados na área costeira da praia de Itaguá, em Ubatuba, SP, à densidade de dois peixes por metro cúbico.

No início da temporada reprodutiva, em janeiro de 2008, 30 exemplares com peso médio de $1.261,11 \pm 449,0 \mathrm{~g}$ e comprimento total de $43,7 \pm 4,3 \mathrm{~cm}$, em jejum por 24 horas, que apresentavam sêmen sob leve pressão abdominal, foram anestesiados com benzocaína a $0,1 \mathrm{~g} \mathrm{~L}^{-1}$. O sêmen foi extraído de cada peixe e colhido com o auxílio de seringas de plástico para insulina, graduadas até $1 \mathrm{~mL}$. A medida do volume foi obtida diretamente na seringa.

A avaliação da qualidade seminal foi feita, individualmente, antes de se realizar a mistura do sêmen dos diversos machos, em partes iguais, para a realização dos experimentos de refrigeração. Foram determinados os seguintes parâmetros: taxa de motilidade espermática, em percentagem de células que apresentam movimento progressivo; duração da motilidade espermática, que é a duração da atividade de movimento celular, medida em segundos; e a concentração espermática, que é o número de espermatozoides por mililitro de sêmen fresco. A análise da motilidade e da duração da motilidade espermáticas foram aferidas simultaneamente, na mesma preparação, por um único técnico que usou um único campo focal escolhido aleatoriamente, com intensidade de luz mantida inalterada. Para a ativação do sêmen, foi utilizada a taxa de diluição de 1:1 semelhante à que utilizaram Sanches et al. (2008) e Tiba et al. (2009) com outras espécies de peixes marinhos -, a qual foi realizada imediatamente após a mistura de sêmen em água marinha (salinidade 35\%o) (15 $\mu \mathrm{L}$ de sêmen: $15 \mu \mathrm{L}$ de água) e observada em microscópio óptico (Zeiss West Germany, Berlim, Alemanha), 
com ampliação de 200x. A motilidade foi estimada subjetivamente, tendo-se registrado a percentagem das células em movimento de deslocamento, visualizadas no campo microscópico. A duração da motilidade foi cronometrada do início da ativação até o momento em que todas as células se tornaram imóveis. A concentração espermática foi avaliada, por meio da contagem em microscópio (200x) das células espermáticas presentes nas amostras de sêmen, previamente diluídas em solução tamponada de formol a $5 \%$, e preparadas em câmara hematimétrica de Neubauer $\left(1 \mathrm{~mm}^{3}\right)$. Para determinação e comparação da concentração espermática, foi empregada a técnica de espermatócrito. O sêmen foi colocado em capilares de micro-hematócrito, com uma das extremidades selada com plastilina, e submetido à centrifugação $18.000 \mathrm{~g}$ por 15 min, em microcentrífuga (Eikonal do Brasil, São Paulo, Brasil). Estes valores haviam sido determinados em um experimento prévio. Após a centrifugação, a leitura da massa celular foi feita com régua graduada, e os valores obtidos foram expressos em percentagem. Foi estimada a correlação entre o espermatócrito e a concentração espermática.

Foram realizados três experimentos. No primeiro, foi avaliado o efeito de diferentes soluções diluidoras, sobre a preservação da motilidade e do tempo de motilidade do sêmen resfriado $\left(4^{\circ} \mathrm{C}\right)$ por até seis dias (144 horas). Foram utilizadas três soluções iônicas A, B e C -, já utilizadas por Sanches et al. (2008) e Tiba et al. (2009). O diluente A ( $\left.\mathrm{g} \mathrm{L}^{-1}\right)$ continha: $\mathrm{NaCl}$, 7,89; $\mathrm{KCl}, 1,19 ; \mathrm{CaCl}_{2}, 0,2 ; \mathrm{MgCl}_{2}, 0,4266 ; \mathrm{pH} 6,1$; $158 \mathrm{mmol} \mathrm{kg}^{-1}$. O diluente $\mathrm{B}\left(\mathrm{g} \mathrm{L}^{-1}\right)$ se compôs de: $\mathrm{NaCl}, 6,5 ; \mathrm{KCl}, 3,0 ; \mathrm{CaCl}_{2}, 0,3 ; \mathrm{NaHCO}_{3}, 0,2 ; \mathrm{pH} 7,8$; $157 \mathrm{mmol} \mathrm{kg}^{-1}$. E o diluente $\mathrm{C}\left(\mathrm{g} \mathrm{L}^{-1}\right)$ continha: $\mathrm{NaCl}, \quad 7,89 ; \mathrm{KCl}, \quad 1,19 ; \mathrm{CaCl}_{2}, \quad 0,22 ; \quad \mathrm{MgCl}_{2}$, 0,72531; $\mathrm{NaH}_{2} \mathrm{PO}_{4}, 0,0805 ; \mathrm{NaHCO}_{3}, 0,84 ; \mathrm{pH} 8,2$; $172 \mathrm{mmol} \mathrm{kg}^{-1}$.

Foi utilizada uma amostra, colhida de 10 indivíduos, composta de quantidades iguais de sêmen que apresentaram motilidade espermática superior a $90 \%$. Utilizou-se o delineamento experimental inteiramente casualizado, com quatro tratamentos e três repetições. Os tratamentos foram: controle, sêmen in natura, sem diluição; $\mathrm{T} 1$, sêmen + diluente $\mathrm{A}$; $\mathrm{T} 2$, sêmen + diluente $\mathrm{B}$; T3, sêmen + diluente C. A proporção sêmen:diluente foi de 1:3 $\left(\mathrm{v} \mathrm{V} \mathrm{V}^{-1}\right)$. As amostras $1 \mathrm{~mL}$ sêmen + diluidor - foram mantidas em tubos de ensaio de $5 \mathrm{~mL}$, devidamente identificadas e armazenadas em refrigerador a $4^{\circ} \mathrm{C}$. As amostras foram agitadas a cada quatro horas, durante todo o período experimental. A taxa de motilidade e a duração da motilidade espermática, de cada unidade experimental, foram avaliadas após $0,12,24,48,72$ e 144 horas de resfriamento a $4^{\circ} \mathrm{C}$. O momento 0 hora da avaliação foi aquele imediatamente após a diluição. Para as análises de viabilidade espermática, foi considerada a premissa de Marques \& Godinho (2004), que definiram como limite para utilização do sêmen uma taxa de motilidade espermática de no mínimo $30 \%$.

No segundo experimento, foi analisado o efeito de diferentes soluções diluidoras sobre a preservação da motilidade e a duração da motilidade do sêmen resfriado a $4^{\circ} \mathrm{C}$ por até dois dias, por meio de atmosfera modificada (exclusivamente oxigênio). Foram utilizadas as mesmas soluções diluentes do experimento anterior. Foi utilizado um "pool" de partes iguais do sêmen de 10 indivíduos - os mesmos do experimento anterior -, com taxa de motilidade espermática superior a $90 \%$. Utilizou-se o delineamento experimental inteiramente casualizado, com quatro tratamentos e três repetições. Os tratamentos foram: controle, sêmen in natura, sem diluição; T1, sêmen + diluente A; T2, sêmen + diluente B; T3, sêmen + diluente C. A proporção sêmen:diluente foi de 1:3 $\left(\mathrm{V} \mathrm{v}^{-1}\right)$. Cada tratamento teve três repetições. As amostras $(1 \mathrm{~mL}$ de sêmen + diluidor) foram mantidas em tubos de ensaio de $5 \mathrm{~mL}$, devidamente identificadas e armazenadas em refrigerador a $4^{\circ} \mathrm{C}$. Todas as amostras foram seladas em um saco de plástico, com capacidade de $60 \mathrm{~L}$, que foi mantido inflado com oxigênio puro. As amostras foram agitadas a cada quatro horas, durante todo o período experimental. A taxa de motilidade e a duração da motilidade espermática, de cada unidade experimental, foram avaliadas após $0,12,24$ e 48 horas de resfriamento a $4^{\circ} \mathrm{C}$. $\mathrm{O}$ momento 0 hora da avaliação foi aquele imediatamente após a diluição.

No terceiro experimento, foram realizados simultaneamente testes de fertilidade do sêmen fresco e refrigerado por 24 e 48 horas, por meio da inseminação de ovócitos oriundos de uma mesma fêmea. Injetou-se na fêmea uma dose única do hormônio LH-RHa (50 $\left.\mu \mathrm{g} \mathrm{kg}^{-1}\right)$ (Western Chemical Inc., Toronto, Canadá). Para este experimento, utilizou-se um "pool" de partes iguais de sêmen de três machos. Este sêmen foi diluído com o diluente $\mathrm{A}$ e submetido à refrigeração em atmosfera normal por 24 e 48 horas. Utilizou-se o 
delineamento experimental inteiramente casualizado, com três tratamentos e dez repetições.

A liberação dos ovócitos maduros teve início 36 horas após a injeção do hormônio, momento em que foi feita a extrusão para os testes de fertilização a seco. Os ovócitos foram recolhidos em bandejas de plástico e divididos em 30 parcelas, com 1.000 ovócitos por parcela, distribuídos em recipientes de plástico de $50 \mathrm{~mL}$ para a fertilização simultânea de 10 parcelas com sêmen fresco, 10 parcelas com sêmen refrigerado por 24 horas e 10 parcelas com sêmen refrigerado por 48 horas. O sêmen fresco, antes de ser misturado, foi diluído no mesmo diluente $\mathrm{A}$ e à mesma proporção utilizada para diluir o sêmen refrigerado.

Após a mistura do sêmen com os ovócitos $-0,05 \mathrm{~mL}$ de sêmen, para cada 1.000 ovócitos, com relação espermatozoide:ovócito de 200.000:1 -, adicionaram-se $20 \mathrm{~mL}$ de água marinha (salinidade 35\%), para ativar os espermatozoides e iniciar a fecundação. $\mathrm{O}$ material correspondente a cada parcela foi posteriormente depositado em incubadoras individuais ( $1 \mathrm{~L}$ ), feitas com tubos de PVC, fechadas na extremidade inferior por uma tela de $500 \mu \mathrm{m}$ e mantidas em flutuação dentro de tanque com circulação contínua de água marinha, à temperatura de $28^{\circ} \mathrm{C}$. A taxa de fertilização, calculada com base na relação entre o número de ovos fertilizados e o número total de ovos, foi estimada quatro horas após a fertilização, no estádio de gástrula. Para estimar a taxa de fertilização, os ovos foram contados em três subamostras de 100 ovos de cada incubadora, pela seguinte equação: taxa de fertilização = número de ovos em divisão/número total de ovos contados.

Para a análise estatística de todos os experimentos, utilizou-se SAS (SAS Institute, 1990). Os dados das taxas de motilidade e de fertilização sofreram transformação angular, antes da análise estatística. A relação matemática entre percentagem de espermatócrito e concentração espermática foi determinada por análise de regressão linear. Todos os dados foram testados quanto à normalidade e homogeneidade das variâncias. Os dados foram submetidos à análise de variância, e as médias foram comparadas pelo teste de Tukey, a 5\% de probabilidade.

\section{Resultados e Discussão}

A taxa de motilidade é um fator chave para se determinar a qualidade do sêmen e a capacidade de fertilização (Rurangwa et al., 2004). O sêmen in natura de $L$. analis apresentou taxa de motilidade de $100 \%$ e duração da motilidade de $174 \pm 29$ s, o que corrobora a afirmação de Lanes et al. (2010) de que a elevada duração da motilidade espermática de algumas espécies de peixes marinhos, em comparação a peixes de água doce, deve-se ao processo ambiental em que é realizada a fecundação (mar aberto), onde fatores hidrodinâmicos são mais intensos, em comparação aos observados na água doce.

A concentração espermática de $L$. analis foi de $2,6 \times 10^{9}$ células $\mathrm{mL}^{-1}$. Riley et al. (2004) obtiveram para Lutjanus campechanus a concentração espermática de $1,0 \times 10^{9}$ células $\mathrm{mL}^{-1}$, e Vuthiphandchai et al. (2009), para Lutjanus argentimaculatus, a concentração de 1,3 a $2,8 \times 10^{10}$ células $\mathrm{mL}^{-1}$. As variações na concentração espermática, de acordo com Godinho (2000), são atribuídas à espécie, à idade dos peixes e aos fatores ambientais (variações ao longo da estação de desova), e o volume de sêmen produzido pelos peixes pode ser muito variável, a depender do tamanho do indivíduo, da época e da metodologia de coleta.

Foi observada uma correlação positiva $(r=0,94)$ entre a concentração espermática e o espermatócrito (Figura 1). A regressão foi significativa $(p<0,05)$ e apresentou elevado coeficiente de determinação $\left(\mathrm{R}^{2}=0,90\right)$; foi possível, portanto, estimar a concentração espermática de L. analis a partir da obtenção do espermatócrito. No linguado, Paralichthys orbignyanus, a técnica do espermatócrito, como método indireto, também permitiu a avaliação da concentração espermática (Lanes et al., 2010).

O sêmen sem a adição de diluentes diferiu significativamente do sêmen com adição de diluentes e apresentou baixa sobrevida (inferior a 24 horas) quando

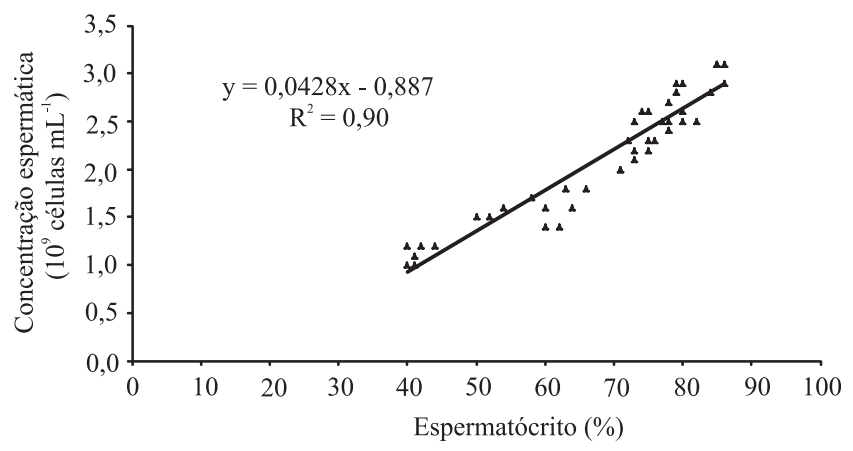

Figura 1. Correlação entre concentração espermática (células $\mathrm{mL}^{-1}$ ) e espermatócrito de sêmen de Lutjanus analis $(\mathrm{n}=30)$. 
refrigerado. Observou-se também que tanto o diluente A como o B foram eficientes em preservar a motilidade espermática (acima de 30\%) por até 72 horas e não diferiram entre si; porém diferiram significativamente do diluente $\mathrm{C}$, que manteve a taxa de motilidade acima de $30 \%$ por apenas 24 horas (Tabela 1 ).

Em relação à duração da motilidade espermática, o sêmen sem adição de diluentes não suportou o rigor do processo de refrigeração e apresentou queda brusca deste parâmetro em apenas 12 horas. Tanto o diluente A como o B foram eficientes em manter a duração da motilidade espermática por até 144 horas, sem diferença entre si, porém diferiram do diluente $\mathrm{C}(\mathrm{p}<0,05)$, que apresentou diminuição da duração da motilidade a partir de 24 a hora de refrigeração (Tabela 1).

A queda gradual na viabilidade do sêmen, ao longo do tempo, observada no presente trabalho, também foi relatada quanto a Pogonias cromis (Wayman et al., 1997), Sciaenops ocellatus (Wayman et al., 1998), Acipenser baerii (Billard et al., 2004), Centropomus undecimalis (Tiersch et al., 2004) e Anguilla anguilla (Peñaranda et al., 2010).

A baixa sobrevida do sêmen de L. analis, quando submetido à refrigeração sem a adição de diluentes, obtida no presente trabalho corrobora os resultados de outros autores com outras espécies de peixes. Sobrevida espermática inferior a 24 horas foi descrita por: Wayman et al. (1997), quanto ao sêmen de P. cromis submetido à refrigeração sem a adição de diluentes; por Wayman et al. (1998), quanto ao sêmen de $S$. ocellatus; e por Tiersch et al. (2004), quanto ao sêmen do robalo-flecha, C. undecimalis. Esses resultados reforçama importância de um diluente adequado para a refrigeração do sêmen de peixes marinhos. Segundo Bezerra (2010), um bom diluente se caracteriza pela osmolaridade adequada à espécie, valor de $\mathrm{pH}$ e poder tampão eficazes, além de uma composição iônica que favoreça a sobrevivência espermática. Estudos recentes (Wilson-Leedy et al., 2009; Alavi et al., 2010) mostraram a importância da osmolaridade e da composição iônica do diluente na preservação da qualidade espermática.

A motilidade espermática pode ser reduzida quando o diluente contiver bicarbonato de sódio, e sua duração está relacionada à dissociação do bicarbonato de sódio em soluções aquosas, que é altamente dependente do $\mathrm{pH}$ do meio aquoso (Tanaka et al., 2002). O bicarbonato de sódio, convertido pela anidrase carbônica em dióxido de carbono $\left(\mathrm{CO}_{2}\right)$, íons de hidrogênio $\left(\mathrm{H}^{+}\right)$e carbonato $\left(\mathrm{HCO}_{3}\right)$, influencia o $\mathrm{pH}$ intracelular dos espermatozoides. Tanaka et al. (2002) demonstraram que o $\mathrm{CO}_{2}$, proveniente da dissociação do bicarbonato de sódio, diminui a motilidade espermática. Garzón et al. (2008) também observaram que modificações nas concentrações de bicarbonato de sódio dos diluentes causaram redução na motilidade espermática na enguia-europeia (Anguilla anguilla).

Os diluentes utilizados no presente trabalho já vêm sendo utilizados, com sucesso, na conservação de sêmen de peixes marinhos (Sanches et al., 2008; Tiba et al., 2009) e se diferenciam por sua composição iônica e valores de $\mathrm{pH}$. O diluente $\mathrm{A}(\mathrm{pH} 6,1)$ difere dos demais pela ausência de bicarbonato de sódio $\left(\mathrm{NaHCO}_{3}\right)$ presente no diluente $\mathrm{B}$ e, em maior quantidade no $\mathrm{C}$, o

Tabela 1. Taxa (\%) e duração da motilidade (s) do sêmen de Lutjanus analis $\left(\mathrm{n}=10\right.$ machos), submetido à refrigeração a $4^{\circ} \mathrm{C}$ e diluído $1: 3\left(\mathrm{v} \mathrm{v}^{-1}\right)$ em diferentes diluentes ${ }^{(1)}$.

\begin{tabular}{|c|c|c|c|c|c|c|}
\hline \multirow[t]{2}{*}{ Diluente $^{(2)}$} & \multicolumn{6}{|c|}{ Tempo de Resfriamento (h) } \\
\hline & 0 & 12 & 24 & 48 & 72 & 144 \\
\hline & \multicolumn{6}{|c|}{ Taxa de motilidade (\%) } \\
\hline A & $100 \pm 0 \mathrm{aA}$ & $95 \pm 3 \mathrm{aA}$ & $93 \pm 3 \mathrm{aA}$ & $57 \pm 8 \mathrm{aB}$ & $48 \pm 7 \mathrm{aB}$ & $29 \pm 5 \mathrm{aC}$ \\
\hline B & $100 \pm 0 \mathrm{aA}$ & $92 \pm 0 \mathrm{aA}$ & $85 \pm 3 \mathrm{aA}$ & $49 \pm 2 \mathrm{aB}$ & $41 \pm 4 \mathrm{aB}$ & $15 \pm 3 b C$ \\
\hline $\mathrm{C}$ & $100 \pm 0 \mathrm{aA}$ & $93 \pm 0 \mathrm{aA}$ & $70 \pm 0 \mathrm{bB}$ & $12 \pm 5 \mathrm{bC}$ & $2 \pm 0 \mathrm{bD}$ & $0 \pm 0 \mathrm{cD}$ \\
\hline \multirow[t]{2}{*}{$\underline{\text { Sêmen não diluído }}$} & $100 \pm 0 \mathrm{aA}$ & $23 \pm 2 b B$ & $0 \pm 0 \mathrm{cC}$ & - & - & - \\
\hline & \multicolumn{6}{|c|}{ Duração da motilidade (s) } \\
\hline A & $169 \pm 8 \mathrm{aB}$ & $280 \pm 33 \mathrm{aA}$ & $220 \pm 21 \mathrm{aA}$ & $210 \pm 75 \mathrm{aA}$ & $190 \pm 26 \mathrm{aB}$ & $70 \pm 15 \mathrm{aC}$ \\
\hline B & $169 \pm 8 \mathrm{aB}$ & $270 \pm 27 \mathrm{aA}$ & $200 \pm 36 \mathrm{aA}$ & $180 \pm 31 \mathrm{aB}$ & $160 \pm 22 \mathrm{aB}$ & $52 \pm 19 \mathrm{aC}$ \\
\hline $\mathrm{C}$ & $169 \pm 8 \mathrm{aB}$ & $250 \pm 18 \mathrm{aA}$ & $110 \pm 11 \mathrm{bB}$ & $60 \pm 8 \mathrm{bC}$ & $20 \pm 2 b D$ & $0 \pm 0 \mathrm{bE}$ \\
\hline Sêmen não diluído & $169 \pm 8 \mathrm{aB}$ & $52 \pm 2 \mathrm{bB}$ & $0 \pm 0 \mathrm{cC}$ & - & - & - \\
\hline
\end{tabular}

${ }^{(1)}$ Médias \pm desvio-padrão seguidas de letras iguais, minúsculas nas colunas e maiúsculas nas linhas, não diferem entre si, pelo teste de Tukey, a $5 \%$ de probabilidade.

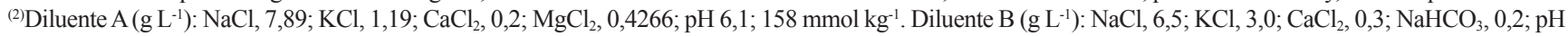
7,$8 ; 157 \mathrm{mmol} \mathrm{kg}^{-1}$. Diluente $\mathrm{C}\left(\mathrm{g} \mathrm{L}^{-1}\right)$ : NaCl, 7,89; KCl, 1,19; $\mathrm{CaCl}_{2}, 0,22 ; \mathrm{MgCl}_{2}, 0,72531 ; \mathrm{NaH}_{2} \mathrm{PO}_{4}, 0,0805 ; \mathrm{NaHCO}_{3}, 0,84 ; \mathrm{pH}^{2}, 2 ; 172 \mathrm{mmol} \mathrm{kg}$. 
que poderia explicar o melhor desempenho do diluente A no processo de refrigeração do sêmen de $L$. analis.

Dois fatores podem ter contribuído para a queda acentuada na taxa de motilidade espermática, observada após 24 horas de refrigeração: a contaminação bacteriana do sêmen, resultante do método de coleta, e a proporção de diluição utilizada. A coleta de sêmen, por meio de massagem abdominal, produz uma alta taxa de contaminação bacteriana, em razão do contato do sêmen com o muco externo do peixe. O prolongamento das condições de estocagem, durante a refrigeração, pode afetar a qualidade do sêmen pelo desenvolvimento de bactérias (Rurangwa et al., 2004). A proporção de diluição utilizada (1:3) para a refrigeração do sêmen de $L$. analis também pode ter contribuído para o baixo tempo de sobrevida do sêmen refrigerado (inferior a 72 horas). A proporção de diluição de 1:50, para a refrigeração do sêmen da enguia-europeia (Anguilla anguilla), proporcionou maior tempo de conservação (Peñaranda et al., 2010). Uma das funções do diluente e, consequentemente, da proporção de diluição, é proteger o sêmen dos efeitos danosos da redução de temperatura (Park \& Chapman, 2005), o que explicaria esta elevação no tempo de conservação do sêmen obtida por esses autores.

No segundo experimento, tanto em relação à taxa de motilidade quanto à duração da motilidade espermática, houve expressiva queda na qualidade seminal, e não foi possível obter tempos de refrigeração superiores a 12 horas, com os resultados mínimos de motilidade (30\%) previamente definidos (Figura 2). A adição de diluentes ao sêmen, em comparação ao sêmen não diluído, diferiu significativamente $(\mathrm{p}<0,05)$, entretanto, não foram observadas diferenças entre os diferentes diluentes utilizados.

A atmosfera exclusiva de oxigênio, durante a refrigeração do sêmen do esturjão-do-Atlântico, Acipenser oxyrinchus, foi utilizada por Dilauro et al. (1994), que relataram taxa de motilidade espermática entre 99 e 40\%, após cinco e 17 dias, respectivamente. Posteriormente, esta técnica foi indicada por Bencic et al. (2000), por proporcionar melhores resultados de sobrevida espermática de salmonídeos submetidos ao processo de refrigeração. O sêmen de Morone saxatilis, refrigerado por 48 horas em atmosfera exclusiva de oxigênio, apresentou taxa de motilidade significativamente superior ao dos refrigerados em atmosfera normal ou em atmosfera exclusiva de nitrogênio (Jenkins-Keeran et al., 2001). Este protocolo foi confirmado por Billard et al. (2004), que destacaram a disponibilidade de oxigênio para as células espermáticas como um ponto crítico na refrigeração do sêmen. Resultados contrastantes, entretanto, foram observados por Saad et al. (1988), na preservação do sêmen da carpa (Cyprinus carpio), em que o oxigênio não produziu vantagem em comparação ao estocado em contato com o ar. Marques \& Godinho (2004) também não encontraram diferenças na viabilidade espermática (taxa de motilidade e duração da motilidade espermática) de seis espécies de peixes
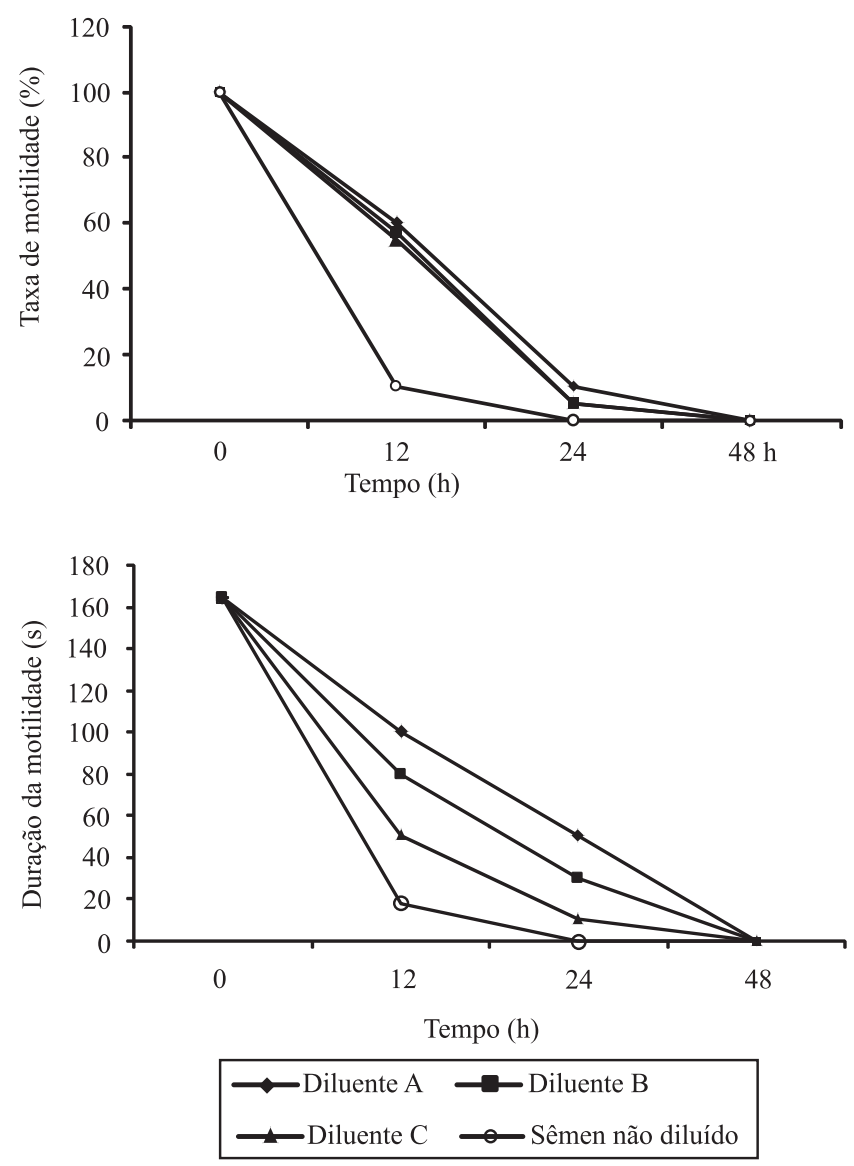

Figura 2. Taxa e duração da motilidade do sêmen de Lutjanus analis ( $\mathrm{n}=10$ machos), submetido à refrigeração a $4^{\circ} \mathrm{C}$, em atmosfera modificada (100\% oxigênio) e diluído a $1: 3\left(\mathrm{v} \mathrm{v}^{-1}\right)$, nos seguintes diluentes: $\mathrm{A}\left(\mathrm{g} \mathrm{L}^{-1}\right)-\mathrm{NaCl}, 7,89 ; \mathrm{KCl}, 1,19 ; \mathrm{CaCl}_{2}, 0,2 ; \mathrm{MgCl}_{2}, 0,4266$; pH 6,1; $158 \mathrm{mmol} \mathrm{kg}^{-1}$; diluente $\mathrm{B}\left(\mathrm{g} \mathrm{L}^{-1}\right)-\mathrm{NaCl}, 6,5 ; \mathrm{KCl}, 3,0$; $\mathrm{CaCl}_{2}, 0,3 ; \mathrm{NaHCO}_{3}, 0,2 ; \mathrm{pH} 7,8 ; 157 \mathrm{mmol} \mathrm{kg}{ }^{-1}$; e diluente $\mathrm{C}\left(\mathrm{g} \mathrm{L}^{-1}\right)-\mathrm{NaCl}, 7,89 ; \mathrm{KCl}, 1,19 ; \mathrm{CaCl}_{2}, 0,22 ; \mathrm{MgCl}_{2}, 0,72531$; $\mathrm{NaH}_{2} \mathrm{PO}_{4}, 0,0805 ; \mathrm{NaHCO}_{3}, 0,84 ; \mathrm{pH} 8,2 ; 172 \mathrm{mmol} \mathrm{kg}{ }^{-1}$. 
tropicais de água doce sulamericanas, quando o sêmen foi mantido em refrigeração, à atmosfera normal e oxigênio puro. A utilização de atmosfera modificada ( $100 \%$ oxigênio) não propiciou vantagens no processo de refrigeração do sêmen de L. analis, com sobrevida espermática pouco superior a 12 horas, que contrastou com as 72 horas obtidas em atmosfera normal.

O tipo de recipiente, utilizado para conter o sêmen diluído, pode influenciar os resultados, quando se analisa o efeito de diferentes tipos de atmosferas durante o processo de refrigeração. Recipientes altos (baixa relação superfície da base:volume) não favorecem uma adequada interface ar e líquido, e é necessária a agitação das amostras ao longo do tempo. Paralelamente, recipientes com ampla superfície e baixo volume favorecem a evaporação e o consequente aumento da viscosidade do sêmen, com redução da sobrevida espermática (Jenkins-Keeran et al., 2001).

Em relação ao experimento de capacidade de fertilização do sêmen refrigerado, a taxa de fertilização, quando se utilizou o sêmen fresco $(72 \pm 5,4 \%)$, não diferiu significativamente da obtida com o uso de sêmen refrigerado por 24 horas $(69 \pm 2,5 \%)$, com diluente A. Entretanto, ambas foram significativamente superiores ao tratamento que utilizou sêmen refrigerado por 48 horas $(38 \pm 5,7 \%)$, com o mesmo diluente.

Vários estudos de refrigeração de sêmen de peixes avaliarama eficiência desta técnica, tendo considerado somente os valores de taxa de motilidade e duração da motilidade espermáticas, e poucos avaliaram a taxa de fertilização como parâmetro eficiente deste procedimento. Altas taxas de fertilização (80 e 90\%) foram obtidas por Marques \& Godinho (2004), com o sêmen refrigerado por até 8 horas de Prochilodus marggravii. Uma taxa de fertilização superior a 50\% foi obtida por Carneiro et al. (2006), que empregaram o sêmen refrigerado por até 12 dias do jundiá Rhamdia quelen. Taxas de fertilização entre $17 \mathrm{e}$ $81 \%$ foram registradas por Riley et al. (2004), com sêmen refrigerado por 24 horas de L. campechanus, cuja variação foi atribuída pelos autores a diferenças na qualidade dos ovos.

Não foram encontrados, na literatura, relatos de fertilização de ovócitos de cioba $L$. analis com sêmen refrigerado.

\section{Conclusões}

1. A refrigeração do sêmen de Lutjanus analis, por até 24 horas, com o diluente $\mathrm{A}$ ( $\mathrm{pH}$ 6,1 sem bicarbonato de sódio), permite taxa de fertilização semelhante à do sêmen fresco e pode ser indicada como alternativa viável durante os processos de reprodução desta espécie.

2. A utilização de atmosfera modificada (100\% oxigênio) na refrigeração do sêmen de $L$. analis não é efetiva na preservação da qualidade seminal.

\section{Referências}

ALAVI, S.M.H.; JORFI, E.; HATEF, A.; MORTEZAVI, S.A.S. Sperm motility and seminal plasma characteristics in Barbus sharpeyi (Günther, 1874). Aquaculture Research, v.41, p.e688-e694, 2010.

BENCIC, D.C.; KRISFALUSI, M.; CLOUD, J.G.; INGERMANN, R.L. Short-term storage of salmonid sperm in air versus oxygen. North American Journal of Aquaculture, v.62, p.19-25, 2000.

BENETTI, D.D.; MATERA, J.A.; STEVENS, O.M.; ALARCÓN, J.F.; FEELEY, M.W.; ROTMAN, F.J.; MINEMOTO, Y.; BANNER-STEVENS, G.; FANKE， J.; ZIMMERMAN, S.; ELDRIDGE, L. Growth, survival, and feed conversion rates of hatchery-reared mutton snapper Lutjanus analis cultured in floating net cages. Journal of the World Aquaculture Society, V.33, p.349-357, 2002.

BEZERRA, F.S.B. Conservação do sêmen caprino sob refrigeração ou congelação. Acta Veterinaria Brasilica, v.4, p.20-25, 2010.

BILLARD, R.; COSSON, J.; NOVEIRI, S.B.; POURKAZEMI, M. Cryopreservation and short-term storage of sturgeon sperm, a review. Aquaculture, v.236, p.1-9, 2004.

BOTERO, J.A.; OSPINA, F.J. Crecimiento de juveniles de pargo palmero Lutjanus analis (Cüvier) en jaulas flotantes en Islas del Rosario, Caribe colombiano. Boletín de Investigaciones Marinas y Costeras, v.31, p.205-217, 2003.

CARNEIRO, P.C.F.; SEGUI, M.S.; IÓRIS FILHO, C.; MIKOS, J.D. Viabilidade do sêmen do jundiá, Rhamdia quelen, armazenado sob refrigeração. Revista Acadêmica Ciências Agrárias e Ambientais, v.4, p.11-16, 2006.

CLARO, R.; LINDEMAN, K.C. Biología y manejo de los pargos (Lutjanidae) en el Atlántico occidental. La Habana: Instituto de Oceanología, 2008. 472p.

DILAURO, M.N.; KRISE, W.F.; HENDRIX, M.A.; BAKER, S.E. Short-term cold storage of Atlantic sturgeon sperm. Progressive Fish-Culturist, v.56, p.143-144, 1994.

FREITAS, L.E.L.; NUNES, A.J.P.; SÁ, M.V. do C. Growth and feeding responses of the mutton snapper, Lutjanus analis (Cuvier 1828), fed on diets with soy protein concentrate in replacement of Anchovy fish meal. Aquaculture Research, v.42, p.866-877, 2011.

Pesq. agropec. bras., Brasília, v.46, n.12, p.1673-1680, dez. 2011 
GARZÓN, D.L.; PEÑARANDA, D.S.; PÉREZ, L.; MARCO-JIMÉNEZ, F.; ESPERT, X.; MÜLLER, T.; JOVER, M.; ASTURIANO, J.F. Effects of $\mathrm{pH}$, sodium bicarbonate, cryoprotectants and foetal bovine serum on the cryopreservation of European eel sperm. Reproduction in Domestic Animals, v.43, p.99-105, 2008.

GODINHO, H.P. Criopreservação de sêmen de peixes. Informe Agropecuário, v.21, p.16-20, 2000.

JENKINS-KEERAN, K.; SCHREUDERS, P.; EDWARDS, K.; WOODS III, L.C. The effects of oxygen on the short-term storage of striped bass semen. North American Journal of Aquaculture, v.63, p.238-241, 2001.

LANES, C.F.C.; OKAMOTO, M.H.; BIANCHINI, A.; MARINS, L.F.; SAMPAIO, L.A. Sperm quality of Brazilian flounder Paralichthys orbignyanus throughout the reproductive season. Aquaculture Research, v.112, p.199-207, 2010.

MARQUES, S.; GODINHO, H.P. Short-term cold storage of sperm from six neotropical characiformes fishes. Brazilian Archives of Biology and Technology, v.47, p.799-804, 2004.

OLIVEIRA, A.V.; VIVEIROS, A.T.M.; MARIA, A.N.; FREITAS, R.T.F.; IZAÚ, Z.A. Sucesso do resfriamento e congelamento do sêmen de pirapitinga Brycon nattereri. Arquivo Brasileiro de Medicina Veterinária e Zootecnia, v.59, p.1509-1515, 2007.

PARK, C.; CHAPMAN, F.A. An extender solution for the short-term storage of sturgeon semen. North American Journal of Aquaculture, v.67, p.52-57, 2005.

PEÑARANDA, D.S.; MARCO-JIMÉNEZ, F.; PÉREZ, L.; GALlEGO, V.; MAZZEO, I.; VICENTE, J.S.; JOVER, M.; ASTURIANO, J.F. Evaluation of different diluents for short-term storage of European eel sperm under air-limited conditions. Journal of Applied Ichthyology, v.26, p.659-664, 2010.

RILEY, K.L.; HOLLADAY, C.G.; CHESNEY, E.J.; TIERSCH, T.R. Cryopreservation of sperm of red snapper Lutjanus campechanus. Aquaculture, v.238, p.183-194, 2004.

RURANGWA, E.; KIME, D.E.; OLLEVIER, F.; NASH, J.P. The measurement of sperm motility and factors affecting sperm quality in cultured fish. Aquaculture, v.234, p.1-28, 2004.
SAAD, A.; BILLARD, R.; THERON, M.C.; HOLLEBECQ, M.G. Short-term preservation of carp (Cyprinus carpio) semen. Aquaculture, v.71, p.133-150, 1988.

SANCHES, E.G.; OLIVEIRA, I. da R.; SERRALHEIRO, P.C. da S. Crioconservação do sêmen da garoupa-verdadeira Epinephelus marginatus. Bioikos, v.22, p.81-90, 2008.

SAS INSTITUTE. SAS technical report. Release 6.11. Cary: SAS Institute, 1990. 229p.

TANAKA, S.; ZHANG, H.; YAMADA, Y.; OKAMURA, A.; HORIE, N.; UTOH, T.; MIKAWA, N.; OKA, H.P.; KUROKURA, $\mathrm{H}$. Inhibitory effect of sodium bicarbonate on the motility of sperm of Japanese eel. Journal of Fish Biology, v.60, p.1134-1141, 2002.

TAN-FERMIN, J.D.; MIURA, T.; ADACHI, S.; YAMAUCHI, K. Seminal plasma composition, sperm motility, and milt dilution in the Asian catfish Clarias macrocephalus (Günther). Aquaculture, v.171, p.323-338, 1999.

TIBA, R.M.; OLIVEIRA, I.R.; SERRALHEIRO, P.C.S.; OSTINI, S. Diluentes e proporções sêmen: diluente na crioconservação do sêmen do robalo-peva Centropomus parallelus. Boletim do Instituto de Pesca, v.35, p.99-110, 2009.

TIERSCH, T.R.; WAYMAN, W.R.; SKAPURA, D.P.; NEIDIG, C.L.; GRIER, H.J. Transport and cryopreservation of sperm of the common snook, Centropomus undecimalis (Block). Aquaculture Research, v.35, p.278-288, 2004.

VUTHIPHANDCHAI, V.; CHOMPHUTHAWACH, S.; NIMRAT, S. Cryopreservation of red snapper Lutjanus argentimaculatus sperm: effect of cryoprotectants and cooling rates on sperm motility, sperm viability and fertilization capacity. Theriogenology, v.72, p.129-138, 2009.

WAYMAN, W.R.; THOMAS, R.G.; TIERSCH, T.R. Refrigerated storage and cryopreservation of black drum (Pogonias cromis) spermatozoa. Theriogenology, v.47, p.1519-1529, 1997.

WAYMAN, W.R.; TIERSCH, T.R.; THOMAS, R.G. Refrigerated storage and cryopreservation of sperm of red drum, Sciaenops ocellatus L. Aquaculture Research, v.29, p.267-273, 1998.

WILSON-LEEDY, J.G.; KANUGA, M.K.; INGERMANN, R.L. Influence of osmolality and ions on the activation and characteristics of zebrafish sperm motility. Theriogenology, v.71, p.1054-1062, 2009.

Recebido em 10 de março de 2011 e aprovado em 11 de novembro de 2011 